\title{
Developing Sustainability Rating System for Healthcare Facilities: Focus on Egypt
}

\author{
Esraa ElMitainy, Salah M. El-Haggar \\ School of Sciences and Engineering, The American University in Cairo, Cairo, Egypt \\ Email: esraa.elmitainy@aucegypt.edu
}

How to cite this paper: ElMitainy, E. and El-Haggar, S.M. (2019) Developing Sustainability Rating System for Healthcare Facilities: Focus on Egypt. Journal of Environmental Protection, 10, 958-971. https://doi.org/10.4236/jep.2019.107057

Received: June 11, 2019

Accepted: July 28, 2019

Published: July 31, 2019

Copyright $\odot 2019$ by author(s) and Scientific Research Publishing Inc. This work is licensed under the Creative Commons Attribution International License (CC BY 4.0).

http://creativecommons.org/licenses/by/4.0/ (c) (i) Open Access

\begin{abstract}
Healthcare is one of the core operating sectors all over the world with a designated Goal 3: Good Health and Well-being of the international Sustainable Development Goal (SDG), while three other goals addressed the eradication of causes of healthcare problems. The World Health Organization (WHO) estimated the increase of healthcare expenditure to be $\$ 2$ - \$4 Billion USD by the year 2030 as a result of Climate change. As a developing country, Egypt has a fast-growing healthcare sector, which is a good opportunity to direct the sector towards a more sustainable development scheme to reduce the cost of the service, while maintaining a high service level for the patience and reducing the environmental impacts of operation, which are the pillars of sustainable development. The aim of the work presented is to develop sustainability rating system for new and existing healthcare facilities suitable to the Egyptian context that encourages the facilities to operate more sustainably using the concept of cradle-to-cradle resources management. The rating system developed is based on a points system with the awardable levels of achievement: Bronze, Silver, Gold and Platinum. The points divided among three main categories: Energy, Water and Habitat, and additionally, two general prerequisites are added for the top management commitment towards sustainability and developing an environmental management plan. The system divides the facilities into new and existing, with each type having different awardable points that take into consideration the differences in applicability between the two types of facilities.
\end{abstract}

\section{Keywords}

Sustainability, Healthcare, Rating System, Cradle-to-Cradle

\section{Introduction}

Healthcare is one of the basic human rights, and to emphasise that importance, 
the Global Sustainable Development Goals (SDGs) directly addressed the issue in Goal 3: "Good Health and Well-being", while three other goals represented in Goal 2: "Zero Hunger", Goal 6: "Clean Water and Sanitation" and Goal 7: "Affordable and Clean Energy", target providing a better life for all humans and as a result the removal of the cause of diseases from source [1].

In general, the environmental risks are estimated to cause 12.6 million deaths per year, approximately $23 \%$ of the total annual deaths, with children under five years old and older adults being the most affected groups [2]. An estimated 5.5 million deaths per year are reported to currently have the root cause as the air pollutants causing climate change [3]. As climate change is considered one of the main causes of adverse health issues, with the expected increase in effect especially in countries of low income, the World Health Organization (WHO) estimates a USD 2 - 4 billion increase in the healthcare expenditure by the year 2030 due to climate change alone [4].

Considering that the healthcare sector is one of the contributors to Green House Gas emissions, and taking into account the complexity of healthcare facilities, it is important for the sector to lead the path towards global sustainability as the main sector that deals with the consequences of business as usual actions [3].

\section{Health Sector Overview}

In 2015, the global healthcare expenditure was reported to be almost USD 1000 per capita, with a share of more than $6 \%$ of the world average Gross Domestic Product (GDP) [5]. The 2019 data showed that the expenditure ranged from $16.8 \%$ of GDP in North America, followed by $10.5 \%$ in Western European countries to only 5.5\% in the Middle East and North Africa [6]. From the year 2000 to 2015, the annual healthcare expenditure growth rate reached $4 \%$ in comparison to the economic growth rate which only reached $2.8 \%$ for the same time period [7].

With the projected increase of average life expectancy from 73.5 in 2018 to reach 74.4 in 2022, the healthcare services expenditure is expected to also increase in the future due to the continuous increase of elderly population, in addition to the technological advancements that are currently being utilized by the sector and the accompanied rise in service providers cost [6] [8].

In the process of offering the healthcare service, the healthcare facilities consume a significant amount of resources to maintain the required service level, starting with the construction materials, and including electricity, water, food and other materials. A fully operating hospital, for example, usually functions 24 hours per day all year long, and some of the services that operate with it include: space cooling, indoor air quality control, lighting, cold and hot water supply, steam supply in addition to the core clinical activities taking place [9].

Studies carried out in developed countries like the United States of America (USA), Australia and the United Kingdom (UK) have reported a Healthcare 
sector contribution to the total Countries' Green House Gas emissions of 8\%, 7\% and 3\%, respectively [10] [11] [12]. Additionally, in a developing country like Brazil Hospitals energy consumption alone was reported to contribute to $10.6 \%$ of the total commercial energy use [13].

The reported high resources consumption intensity and accompanying climate footprint is often seen as a chance for healthcare facilities to become more sustainable, especially with the moral responsibility of the health sector to lead by example and reduce the sector's contribution to climate change. On a global level, facilities that apply the concept of Green Hospitals can achieve very good cost savings and Greenhouse Gases emissions reduction from energy efficiency measures alone, in addition to the possible utilization of alternative energy sources, more sustainable water consumption, waste management and an enhanced healing environment all over [9] [14] [15] [16].

\section{Health Sector in Egypt}

On the regional level, the Eastern Mediterranean countries, including Egypt, have around $22 \%$ of the deaths attributed to environmental caused diseases [2]. The cost of healthcare services in Egypt reached USD 131 per Capita in 2016 with $4.6 \%$ share of GDP, yet $62 \%$ of the total cost was attributed to out-of-pocket expenditure. Although the expenditure figure seem to be much lower than the world average, the out-of-pocket spending can be considered high compared to the governmental health expenditure level [17].

Until 2014, Egypt had around 2600 fully operating hospitals with more than 130 thousand beds. The ownership of these facilities is $68 \%$ to the private sector, and $32 \%$ public sector distributed between governmental and semi-governmental institutions. However, the number of beds distribution is only $43 \%$ for the private section, while the rest are served by the public sector hospitals [18]. The current number of bed availability is reported at $1.5 / 1000$ persons in comparison to the world average of $2.7 / 1000$, which means that there is a high potential for the sector to grow still [19].

Although no comprehensive studies were published to date to report the overall share of energy consumption or greenhouse gas emissions by the healthcare sector independently, a case study done on a hospital in Egypt has found out that applying energy efficiency measures can result in a $2.5 \%$ to more than $40 \%$ reduction in energy consumption per year depending on the intervention level whether small measures to an existing facilities or a possible early intervention in the design stage [20].

The main objective of the work presented is to develop a Sustainability Rating system for healthcare facilities in developing countries having prevalent hot dry conditions, taking the Egyptian Conditions as an example. The proposed system is based on the international standards and follows the cradle-to-cradle concept, which is considered a new approach for facilities to manage their resources in a method that targets closing the life cycle of the materials consumed over the life- 
time of the project, starting from construction, operation and demolition, and to divert any waste from being disposed in landfills, thus reducing the activity footprint to a minimum.

\section{Sustainable Healthcare Facilities}

In the efforts to promote Green Buildings, including healthcare facilities, several guidelines were prepared originating from different countries covering both, new and/or existing facilities, some with context more relevant to the country of issuing, similar to the proposed system that is discussed in this work, and some are prepared for international use regardless of the region of implementation.

One of the earliest established rating systems is the Building Research Establishment Environmental Assessment Method (BREEAM) which is developed by the Building and Research Establishment Group (BRE Group), which is originally based in the United Kingdom (UK). The system currently has two standards covering new facilities and major renovations of healthcare facilities, one developed specifically for the UK ("BREEAM UK New Construction: Non-domestic Buildings"), and the other is "BREEAM International New Construction", which was issued in 2016 covering hospitals and other healthcare facilities, and replacing the 2008 healthcare scheme document. A separate standard is developed for the existing non-domestic facilities which is "BREEAM In-Use International-Technical Manual” [21] [22] [23]. The most famous rating system is the Leadership in Energy and Environmental Design (LEED ${ }^{\circledR}$ ) Rating system which is developed by the U.S. Green Building Council. The LEED ${ }^{\circledR}$ rating system which addresses the healthcare facilities, among others, is the version 4 for Building Design and Construction, which covers new facilities and major renovations, while the "Building Maintenance and Operation v4" does not cover healthcare facilities [24]. Another rating system that in the year 2017 integrated the healthcare sector into the general system is the Australian "Green Star-Design \& As Built" rating system which is developed by the Green Building Council of Australia [25].

Other rating systems are in place for developing countries like the ones developed by example Malaysia and Singapore. Malaysia has the Green Building Index (GBI) rating systems which address hospitals with separate criteria and cover both new and existing facilities in the "Non-residential New Construction (NRNC): Hospital version 1.0" and "Non-Residential Existing Building (NREB): Hospital version 1.0", respectively [26] [27]. While Singapore's rating system is developed by the Building and Construction Authority (BCA) with designated version for the healthcare sector under the title "BCA Green Mark for Healthcare Facilities version 1.0" [28].

Although the number and titles assigned to the criteria categories differed from one rating system to the other, the rating system guidelines in general included 6 and to 10 different categories covering aspects such as: energy, water, materials and resources, site management, transportation, indoor and outdoor 
pollution, as well as innovation. Each category contained the relevant prerequisites and awardable points assigned by the system experts in accordance to their views of the priority points that need addressing in the targeted implementation area.

The current situation in Egypt is that several laws, regulations and guidelines govern the building and operation of healthcare facilities with the main legislator responsible for granting the operation licenses being the Ministry of Health and Population. Specifically for new facilities, a design and construction guideline was issued by the Housing and Building Research Center (HBRC) under the Ministry of Housing to state the minimum requirements that should be adhered to during the design of different types of healthcare facilities to ensure a high quality design that fits the purpose of the facility in offering high quality services, the HBRC building guidelines should be applied by all new buildings after the year 2015, however the guidelines for existing facilities upgrade is not yet binding by law to be applied. Specifically for the waste disposal, the Ministry of Environment is also involved, and guidelines were issued for the safe handling and disposal of waste, specially the hazardous and clinical waste [18] [29].

Developing a sustainability rating system based on the international best practices and fitting to the Egyptian local conditions, taking into consideration the weather, land use and availability of materials became a necessity with the increased risks due to climate change and water scarcity, as well as the need for elevated energy efficiency became core needs to guarantee the sustainable development of residential buildings, communities, schools and commercial areas [30].

\section{Methodology}

In order to develop the proposed rating system, first the applicable laws and regulations were studied to know the base which must be followed, especially concerning energy, water, waste disposal, and the indoor environment. These laws, regulations and guidelines can be viewed as the basis of any facility that should be abided by and the proposed sustainability measures are efforts exerted over these regulations to drive the road to sustainability.

Afterwards, several international standards were reviewed and consulted, varying from the most well-established standards namely LEED and BREEAM, and additionally including rating systems from developing countries that have nearly similar conditions to the Egyptian Context.

With the aim of facilitating the implementation of the system the proposed criteria are divided into three main categories only, namely: Energy, Water and Habitat, taking into consideration the inclusion of the aspects deemed applicable from the international rating systems. The criteria and its relvant weight is determined using the following methodology:

- Action points that should be fulfilled by the facility as a basic requirement are defined as prerequisites; 
- Optional criteria are assigned a minimum score of 1 awardable upon the criteria implementation;

- Criteria that are judged to be harder to implement or require high investment are assigned higher scores, which are divided into smaller milestones with the highest awardable the full score; and

- The total score of all the optional criteria is kept at a maximum of 100 points. The proposed rating system encourages the sector to go above and beyond the measures dictated by the laws and regulations, towards a more sustainable design, build and operation aiming to close the loop of consumption through applying the Cradle-to-Cradle concept. The Cradle-to-cradle principal of resources management is a new approach used to ensure the maximum utilization of resources without directing any of it to landfills [31].

\section{Proposed Sustainability Rating System for Healthcare Facilities in Egypt}

\subsection{Proposed Criteria and Scorecard}

The rating system' criteria are developed separately for both the New and Existing facilities, this is mainly due to the difference in the condition of each type of facility, for example the applicability of the HBRC design and construction guidelines as part of the new facilities permit process which was not applied to most of the existing facilities. For the proposed system application, the facilities will be categorized at the time of intent to follow the rating system criteria, where New facilities will be considered as projects that are still under planning with the ability to take into consideration the criteria in the design phase, and the same treatment will also be applied to extensions to already existing facilities, while Existing facilities are those already constructed whether operation is already proceeding or still in the commissioning stage of operation.

The differences in the expected intervention level during the transition towards sustainability deemed it necessary that some of the criteria are not equally weighted to account for the different implantation hardships between upgrading an existing situation and implementing a measure from the design phase. The proposed system is discussed below starting with the two general prerequisites, followed by the three criteria categories: Energy, Water and Habitat.

\subsection{General Prerequisites}

To begin the criteria general prerequisites that is overarching before the different assessment categories is developed which is the Top management sustainability commitment and having an environmental management plan in place, as shown in Table 1, and being prerequisites, these criteria do not award the facility any points. The top management commitment prerequisite can be accomplished in the form of a policy that is signed by the management representative to include the points of focus towards sustainability that will be undertaken by the facility and the associates, from the design and construction phase to the operation 
phase. The sustainability commitment document should be communicated to the different service providers and suppliers that are planning to work with the facility to clarify the expected sustainability requirements. While the environmental management plan should cover all the environmental standards to be complied with and the monitoring parameters, the plan can be an adaptation of the one presented in the Environmental Impact Assessment study that is required for any new facility, or can alternatively be counted if the facility is implementing an environmental management system, for example ISO 14001.

Table 1. General prerequisite for the proposed rating system for new and existing healthcare facilities.

\begin{tabular}{lccc}
\hline $\begin{array}{c}\text { Prerequisite/ } \\
\text { Credit }\end{array}$ & Criteria Name & \multicolumn{2}{c}{ Awardable Score } \\
\cline { 3 - 3 } Prerequisite & Top Management Sustainability & New Facilities & Existing Facilities \\
Prerequisite & Eommitment & Required & Required \\
\hline
\end{tabular}

\subsection{Energy Category}

Energy is the first section of the rating system that is designed to cover all the criteria related to electricity and other fuels consumption for the different facility activities including lighting, air circulation, cooling and hot water generation, as mentioned in Table 2. All these activities are considered essential for any healthcare facility operation, as well as being a major contributor to the greenhouse gas emissions from the facility makes them essential to be addressed, especially with the knowledge that a number of measures can have a great impact towards a more energy efficient operation [9].

Table 2. Energy section criteria with assigned scores.

\begin{tabular}{|c|c|c|c|}
\hline \multirow{2}{*}{$\begin{array}{l}\text { Prerequisite/ } \\
\text { Credit }\end{array}$} & \multirow{2}{*}{ Criteria Name } & \multicolumn{2}{|c|}{ Awardable Score } \\
\hline & & New Facilities & Existing Facilities \\
\hline Prerequisite & Energy Management Plan & Required & Required \\
\hline Prerequisite & Commissioning & Required & N/A \\
\hline E01 & Window-to-Wall Ratio & 1 & 1 \\
\hline E02 & Reflective Roof Materials & 1 & 1 \\
\hline E03 & Reflective Paint for External Walls & 2 & 2 \\
\hline E04 & External Shading Devices & 1 & 1 \\
\hline E05 & Roof Insulation & 2 & 2 \\
\hline E06 & External Walls Insulation & 2 & $\mathrm{~N} / \mathrm{A}$ \\
\hline E07 & High Performance Glazing for Windows & 1 & 1 \\
\hline E08 & Air Tightness & 1 & 1 \\
\hline E09 & $\begin{array}{l}\text { HVAC System Efficiency/Ventilation/Air } \\
\text { Conditioning }\end{array}$ & 5 & 5 \\
\hline
\end{tabular}




\section{Continued}

\begin{tabular}{llll}
\hline E10 & Air Filters Suitable to surrounding air quality & 1 & 1 \\
E11 & Enhanced Refrigerant & 1 & 1 \\
E12 & Efficient Interior Lighting & 1 & 1 \\
E13 & Daylight/Lighting Control Sensors & 2 & 2 \\
E14 & Efficient Lighting for External areas & 1 & 1 \\
E15 & Light Pollution Prevention & 1 & 1 \\
E16 & Hot Water & 3 & 3 \\
E17 & Pump Motor Efficiency & 1 & 1 \\
E18 & Energy Metering & 1 & 1 \\
E19 & Renewable Energy & 2 & 2 \\
E20 & Vertical Transportation & 2 & 2 \\
E21 & Energy Efficient Equipment & 2 & 2 \\
E22 & Boiler Efficiency & 4 & 4 \\
E23 & Innovation and Creativity in Energy & 1 & 1 \\
\hline
\end{tabular}

"Total Energy Awardable Points (New: 39, Existing: 37).

The level of applicable interventions related to energy are different between new and existing buildings, therefore, some of the section points are only awardable for New facilities that are still undergoing the design phase, such as the prerequisite of Commissioning, and the credit E06 External Wall insulation, which result in the total awardable points for this section are more for New facilities than they are for existing ones. In general, it is recommended to communicate the performance requirements as early on to allow for flexibility in applying the settled on measures, to reduce the cost and materials waste of alterations after construction, for example the credit E01 window-to-wall ratio, and E09 HVAC system efficiency and ventilation should be correctly designed from the beginning due to their large contribution to energy efficiency which can reach around $4 \%$ and $35 \%$, respectively, compared to the conventional methods and in accordance to the building status [20].

\subsection{Water Category}

Another major resource that is consumed in healthcare facilities is water, which is the second focus category with the assessment criteria discussed in Table 3. Water is a very valuable resource, and especially with the rising freshwater scarcity problem, conserving every drop of water became essential. Healthcare facilities consume water similar to other buildings, but with the specific case of fully operating hospitals the consumption can be in many different areas for several purposes, for example: hot and cold water are used in clinical activities areas, patients' rooms, kitchen and cafeterias, laundry areas, as well as in the form of steam which is produced on site from boilers. 
Table 3. Water section criteria with assigned scores.

\begin{tabular}{llll}
\hline \multirow{2}{*}{$\begin{array}{lll}\text { Prerequisite/ } \\
\text { Credit }\end{array}$} & Criteria Name & \multicolumn{2}{l}{ Awardable Score } \\
\cline { 3 - 4 } Prerequisite & Water and Wastewater Management Plan & Required & Required \\
W01 & Water Efficient Landscaping & 2 & 2 \\
W02 & Irrigation Efficiency & 2 & 2 \\
W03 & Rainwater and A/C condensate Harvesting & 2 & 2 \\
W04 & Greywater Treatment and Reuse & 3 & 3 \\
W05 & Water Metering & 1 & 1 \\
W06 & Water and Wastewater Quality Monitoring & 2 & 2 \\
W07 & Water Saving Devices & 3 & 3 \\
W08 & Water efficient appliances/ Equipment & 2 & 2 \\
W09 & $\begin{array}{l}\text { Innovation and Creativity in Water } \\
\text { Management }\end{array}$ & 1 & 1 \\
\hline
\end{tabular}

"Total Water Awardable Points (New: 18, Existing: 18).

A category prerequisite is that the water and wastewater management actions that are designed or planned to be implemented within the facility should be recorded in the form of a plan to guarantee the official status of these actions. In order to address the water consumption amount, one of the points of focus is the use of water saving devices in all areas including faucets, showerheads and toilet flushing tanks in all installed areas is stressed upon through credit W07. A control tool that is recommended to be used by all types of facilities is W05 water metering that can be used to monitor the consumption and stand on the effectiveness of the implemented measures, as well as to detect any leaks as soon as they occur, with separate water meters installed according to the types of water streams and the size of the facility. As landscape areas can be considered a major water consumer, W02 irrigation efficiency addresses the use of weather resistant plants and efficient irrigation systems, the reuse of treated greywater for different activities is also encouraged through credits W04, on the condition that the reuse practice does not affect the overall service quality, which is monitored by credit point W06, as the patients well-being remains the main target of any healthcare facility.

\subsection{Habitat Category}

The third and last category is habitat, and to facilitate its use, the category covers all the other aspects that are not covered in water in energy, including: sustainable site management, indoor environmental quality and materials and resources use. Table 4 includes the rating criteria for habitat, which is, in contrast to the energy category, the awardable points ire more for existing facilities than for new buildings in this section, and that is due to the fact that existing facilities often need more monitoring and upgrading of their existing conditions to enhance the 
overall healing environment, while new facilities' design has already taken into consideration the new available technologies.

Table 4. Habitat section criteria with assigned scores.

\begin{tabular}{|c|c|c|c|}
\hline \multirow{2}{*}{$\begin{array}{l}\text { Prerequisite/ } \\
\text { Credit }\end{array}$} & \multirow{2}{*}{ Criteria Name } & \multicolumn{2}{|c|}{ Awardable Score } \\
\hline & & New Facilities & Existing Facilities \\
\hline Prerequisite & Construction Activity Pollution Prevention & Required & $\mathrm{N} / \mathrm{A}$ \\
\hline Prerequisite & Solid Waste Management Plan & Required & Required \\
\hline H01 & $\begin{array}{l}\text { Heat Island Reduction: Reflective Materials for } \\
\text { Outdoor Paving }\end{array}$ & 1 & 1 \\
\hline H02 & $\begin{array}{l}\text { Heat Island Reduction: Shaded Parking and/or } \\
\text { underground parking }\end{array}$ & 2 & 2 \\
\hline H03 & Carpool & 1 & 1 \\
\hline $\mathrm{H} 04$ & Open Space/ Places of Respite & 2 & 2 \\
\hline H05 & Design for individuals with special needs & 1 & 1 \\
\hline H06 & Green Roof/ Green Walls & 2 & 2 \\
\hline H07 & Preventive and Corrective Maintenance & 1 & 4 \\
\hline H08 & $\begin{array}{l}\text { Construction and Demolition Waste } \\
\text { Management }\end{array}$ & 3 & N/A \\
\hline H09 & Municipal Waste Management & 3 & 4 \\
\hline $\mathrm{H} 10$ & Medical Waste Management & 5 & 6 \\
\hline H11 & $\begin{array}{l}\text { Environmentally Friendly Materials and } \\
\text { furnishings }\end{array}$ & 3 & 3 \\
\hline H12 & Local Materials & 2 & 1 \\
\hline $\mathrm{H} 13$ & Recycled Content & 2 & 1 \\
\hline H14 & $\begin{array}{l}\text { Persistent Bioaccumulative Toxic (PBT) } \\
\text { chemicals reduction (Mercury, lead, cadmium } \\
\text { and copper) }\end{array}$ & 2 & 2 \\
\hline H15 & Materials Radioactivity Minimization & 1 & 1 \\
\hline H16 & Indoor Environment Quality Monitoring & 2 & 2 \\
\hline $\mathrm{H} 17$ & Rooms Overcrowding Prevention & N/A & 1 \\
\hline $\mathrm{H} 18$ & Windows for Living Spaces & 2 & 2 \\
\hline H19 & Entryway System & 1 & 1 \\
\hline $\mathrm{H} 20$ & Designated Area for Smoking & 1 & 1 \\
\hline $\mathrm{H} 21$ & Kitchen/ Pollutants Exhaust & 2 & 2 \\
\hline $\mathrm{H} 22$ & Kitchen Hygiene and Food Quality & $\mathrm{N} / \mathrm{A}$ & 1 \\
\hline $\mathrm{H} 23$ & Insects and Pest Control & 1 & 1 \\
\hline $\mathrm{H} 24$ & Certified Green Expert & 1 & 1 \\
\hline $\mathrm{H} 25$ & Green Education & 1 & 1 \\
\hline $\mathrm{H} 26$ & Innovation and Creativity in Habitat Design & 1 & 1 \\
\hline
\end{tabular}

"Total Habitat Awardable Points (New: 43, Existing: 45). 
The cradle-to-cradle management concept is stresses upon the most in this category, especially in the materials and resources related criteria, as they tackle the sustainable materials choice and use, and the management of all the waste types, whether municipal, clinical or chemical. As a prerequisite, a solid waste management plan should be prepared that includes the different assigned roles and responsibilities regarding the different stages of waste management within the facility, and states clearly the products purchasing policy adopted, and the acceptable level of waste disposal even if the actual action is to be taken outside the property itself. The achievement of credits $\mathrm{H} 08$ to H10 requires first the proper separation of all waste types from the generation source, and the close monitoring of these waste streams during handling and transportation to avoid contamination, specifically $\mathrm{H} 10$ medical waste which also includes chemical wastes and can cause a whole batch of waste to be considered as hazardous waste. Also, as an encouragement of the total material recovery content the facility is not only encouraged to use local materials (H12) as much as possible in all the construction and furniture acquisition, but to additionally use recycled materials (H13) whenever available. A specific criterion for healthcare facilities is H14 Persistent Bio-accumulative Toxic (PBT) chemicals reduction which requires the careful choice of materials that are low emitting of these chemicals, an issue that is considered essential to enhancement of the conditions to which patients are admitted.

Several critical operational categories are also covered in the habitat category, which addresses the general site conditions inside the facility building as well as outside, with the aim to promote the importance of maintaining the site in general through the project lifetime through $\mathrm{H} 07$ preventive and corrective maintenance, this category is awardable to new facilities based on developing a plan, but requires further tangible actions from existing facilities. Additionally, for the existing facilities, the indoor air quality and facility conditions are considered critical operational quality parameters which are targeted by credits H16 air quality indoors, $\mathrm{H} 17$ rooms overcrowding, $\mathrm{H} 22$ kitchen hygiene and food quality and $\mathrm{H} 23$ insect and pest control activities, which are all points that should exhibit good practice conditions within the facility.

\subsection{System Awardable Levels}

Healthcare facilities applying the proposed rating system, whether new or existing, can achieve one of four possible award levels through implementing the criteria with the credit points. These points however cannot be calculated without first complying with the general prerequisites and the prerequisites of each of the energy, water and habitat categories.

The four awardable level are Bronze, Silver, Gold and Platinum, with scores of more than 40 points, 50 points, 60 points and 70 points, respectively, as shown in Figure 1. The highest achievable level, which is the Platinum level, can be achieved according to the proposed rating system by reaching only 70 points, in 


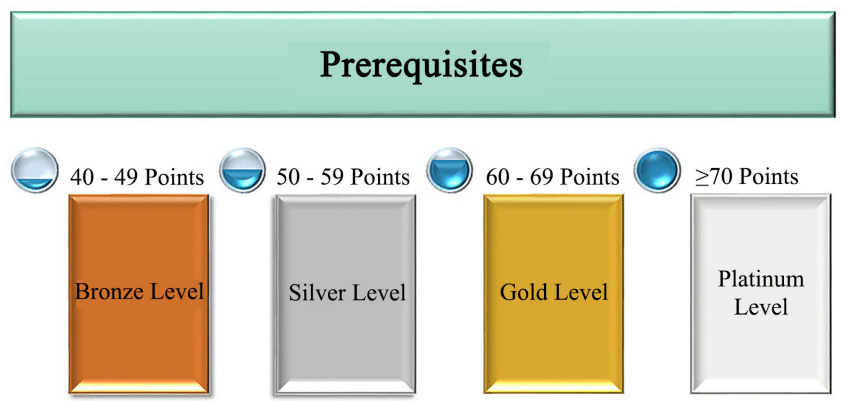

Figure 1. Proposed healthcare rating system awardable levels.

comparison to the LEED which awards the platinum level with $80+$ points, this difference aims to make the level more achievable to encourage the implementation within the Egyptian context.

\section{Conclusions}

Universal healthcare is one of the focus points of the 2030 SDGs worldwide, and the eradication of the causes of health conditions deterioration is also clarified by several international organizations. Considering the potential for the Healthcare sector expansion to satisfy the service availability need, especially in developing countries like Egypt, it is recommended that the healthcare facilities lead to the way towards sustainable operation. Sustainability in relation to healthcare facilities aims to reduce the facilities' impact on the environment, without an added economic burden while maintaining or even improving the service quality provided to the society.

To support the healthcare facilities in this transition, a sustainability rating system is proposed addressing the three main issues of energy, water and habitat in a simplified form suitable for the current targeted implementation levels, and at the same time based on the lessons learned from the international Green buildings rating systems that have been long in operation. The rating system is prepared following the cradle-to-cradle concept of consumption with a focus on all materials life cycle maximization, which is different from the efficient buildings concept that is usually followed by existing systems.

\section{Conflicts of Interest}

The authors declare no conflicts of interest regarding the publication of this paper.

\section{References}

[1] United Nations (UN) (2015) Sustainable Development Goals: 17 Goals to Transform Our World. http://www.un.org/sustainabledevelopment/sustainable-development-goals/

[2] Prùss-Ustùn, A., Wolf, J., Corvalàn, C., Bos, R. and Neira, M. (2016) Preventing Disease through Healthy Environments: A Global Assessment of the Burden of Disease from Environmental Risks. Engenharia Sanitaria e Ambiental, 12, 115-116. 
https://doi.org/10.1590/S1413-41522007000200001

[3] The World Bank (2017) Geographic Hotspots for World Bank Action on Climate Change and Health. World Bank Group, Washington DC.

[4] World Health Organization (WHO) (2013) Protecting Health from Climate Change: Vulnerability and Adaptation Assessment. World Health Organization, Geneva.

[5] World Health Organization (WHO) (2018) Global Health Expenditure Database: World Averages for Key Indicators. https://apps.who.int/nha/database/Regional_Averages/Index/en

[6] Deloitte (2019) 2019 Global Health Care Sector Outlook: Shaping the Future.

[7] Xu, K., Soucat, A., Kutzin, J., Brindley, C., Dale, E., Van de Maele, N., et al. (2018) New Perspectives on Global Health Spending for Universal Health Coverage. World Health Organization (WHO), Geneva, 44.

http://apps.who.int/iris/bitstream/handle/10665/259632/WHO-HIS-HGF-HFWorki ngPper-17.10-eng.pdf;jsessionid=FD27C73861607BD2605E3EECE33CBBD6?seque $\underline{\text { nce }=1}$

[8] The Economist Intelligence Unit (2018) World Industry Outlook, Healthcare and Pharmaceuticals.

[9] Dhillon, V.S. and Kaur, D. (2015) Green Hospital and Climate Change: Their Interrelationship and the Way Forward. Journal of Clinical and Diagnostic Research, 9, LE01-LE05.

[10] Chung, J.W. and Meltzer, D.O. (2009) Estimate of the Carbon Footprint of the US Health Care Sector. American Medical Association, 302, 1970-1972. https://doi.org/10.1001/jama.2009.1610

[11] Malik, A., Lenzen, M., McAlister, S. and McGain, F. (2018) The Carbon Footprint of Australian Health Care. The Lancet Planetary Health, 2, e27-e35.

[12] NHS Sustainable Development Unit (2016) Carbon Footprint Update for NHS in England 2015. Sustainable Development Unit, Fulbourn, Cambridge.

[13] Salem Szklo, A., Soares, J.B. and Tolmasquim, M.T. (2004) Energy Consumption Indicators and CHP Technical Potential in the Brazilian Hospital Sector. Energy Conversion and Management, 45, 2075-2091. https://doi.org/10.1016/j.enconman.2003.10.019

[14] World Health Organization (WHO) and Health Care without Harm (2009) Healthy Hospitals, Healthy Planet, Healthy People: Addressing Climate Change in Health Care Settings.

[15] Kumar, S. and Kapoor, R. (2009) Energy Efficiency in Hospitals: Best Practice Guide. USAID, ECO-III, BEE, India.

[16] Health Care without Harm (HCWH) and Global Green and Healthy Hospitals (GGHH) (2016) Global Green and Healthy Hospitals Annual Report 2016.

[17] World Health Organization (WHO) (2018) Global Health Expenditure Database: Egypt Country Profile. https://apps.who.int/nha/database/country_profile/Index/en

[18] National Solid Waste Management Program (NSWMP) (2015) Health-Care Waste Management in Egypt-Guidelines. Ministry of Environment, Cairo, Egypt.

[19] Colliers International (2017) The Pulse: Egypt Healthcare. 7th Edition, Colliers International, Toronto.

[20] Radwan, A.F., Hanafy, A.A., Elhelw, M. and El-Sayed, A.E.H.A. (2016) Retrofitting of Existing Buildings to Achieve Better Energy-Efficiency in Commercial Building 
Case Study: Hospital in Egypt. Alexandria Engineering Journal, 55, 3061-3071. https://doi.org/10.1016/j.aej.2016.08.005

[21] BRE Global Limited (2018) BREEAM UK New Construction: Non-Domestic Buildings-Technical Manual.

[22] BRE Global Limited (2016) BREEAM International New Construction: Technical Manual.

[23] BRE Global Limited (2015) BREEAM in-Use International-Technical Manual.

[24] US Green Building Council (USGBC) (2014) LEED v4 for Building Design and Construction.

[25] Green Building Council of Australia (GBCA) (2017) Rating System: Design \& As Built. https://new.gbca.org.au/green-star/rating-system/design-and-built/

[26] Green Building Index (GBI) (2015) GBI Non-Residential New Construction (NRNC): Hospital. Kuala Lumpur, Malaysia.

[27] Green Building Index (GBI) (2015) GBI Non-Residential Existing Building (NREB): Hospital. Kuala Lumpur, Malaysia.

[28] Building and Construction Authority (BCA) (2014) BCA Green Mark for Healthcare Facilities. Building and Construction Authority, Singapore.

[29] Housing and Building Research Center (HBRC) (2010) Design Guidelines for Hospitals and Healthcare Facilities. Cairo, Egypt.

[30] Bampou, P. (2017) Green Buildings for Egypt: A Call for an Integrated Policy. International Journal of Sustainable Energy, 36, 994-1009. https://doi.org/10.1080/14786451.2016.1159207

[31] El-Haggar, S.M. (2007) Sustainable Industrial Design and Waste Management: Cradle-to-Cradle for Sustainable Development. Elsevier, ¡Amsterdam, Netherlands. 